\title{
Chemical property of soil and mycorrhizal status in Allanblackia floribunda Oliver (Clusiaceae)
}

\author{
Tchinmegni Felenou I ${ }^{1 *}$, Tsobeng Alain Calice ${ }^{2}$, Ngonkeu Mangaptché Eddy \\ Leonard $^{1,3,4}$ Tchoundjeu Zacharie. ${ }^{1,2}$ \\ ${ }^{1}$ Higher Institute of Environmental Science (HIES), Yaoundé-Cameroon \\ ${ }^{2}$ World Agroforestry Centre (ICRAF), Yaoundé-Cameroon \\ ${ }^{3}$ University of Yaounde I (UYI), Yaoundé-Cameroon \\ ${ }^{4}$ Institute of Agricultural Research for Development (IRAD), Yaoundé-Cameroon
}

\begin{abstract}
The objective of this study was to describe the type of mycorrhizal fungus that is associated with A. floribunda and evaluate the effect of soil chemical properties on its rhizosphere, its mycorrhizal dependency in its natural range in four populations of the species (Mouanko, Yalpenda, Nkenlikok and Mbalmayo), two land use systems (disturbed and undisturbed), two age classes (circumference less than $50 \mathrm{~cm}$ and up to $50 \mathrm{~cm}$ ). Results obtained so far demonstrated that A. floribunda is colonized by arbuscular mycorrhizas. Root colonization was significantly $(\mathrm{P}<0.01)$ different in the targeted populations with the highest observed in Yalpenda $(53.63 \pm 1.33 \%)$. Land disturbance significantly $(\mathrm{P}<0.01)$ affected root colonization. Unperturbed soils displayed the highest root colonization $(35.29 \pm 0.70 \%)$. Age classes had significant $(\mathrm{P}<$ 0.001 ) influence on root colonization and trees with circumferences up to $50 \mathrm{~cm}$ had the highest percentage $(35.45 \pm 0.72 \%)$. There was no significant correlation between root colonization and phosphorus $\left(\mathrm{R}^{2}=0.437, \mathrm{p}\right.$ $=0.563)$, in contrary to root colonization and copper $\left(\mathrm{R}^{2}=-0.934, \mathrm{p}=0.046\right)$. These results constitute a prerequisite for the inoculation phase and molecular analysis of roots already begun.
\end{abstract}

Keywords: Allanblackia floribunda, arbuscular mycorrhizal fungi, root colonization,

\section{INTRODUCTION}

Allanblackia floribunda is a tree of tropical forest ecosystems. It is a multipurpose species, the root bark and leaves have medicinal value. A. floribunda also provides fodder, firewood or lumber (Anegbeh et al., 2006). The oil from its seeds is rich in fatty acids and valued for its oleic and stearic known to lower cholesterol levels in human plasma while reducing the risk of heart attack (Bonanome and Grundy, 1988). Furthermore this oil is used in cosmetics and food industries. Today the seed supply chain is developed by Unilever promises an even greater value of the species. More the novella partnership (public-private) subsidizes the supply of seed but the amounts collected remain inadequate, yet this forest product is experiencing a renewed interest due to the increasing demand on the world market. Currently more than 100000 tonnes of oil Allanblackia SPP is requested each year, but only about 200 tons are supplied on average, due to low amounts of harvested seed (ICRAF, 2011). However, the combined effects of random climatic factors and human action, this forest species has experienced a deterioration jeopardizing oil production and the income of farmers in Cameroon. Since then, many initiatives have been undertaken to ensure sustainable access of local populations and large international firms such UNILEVER, with multiple services and products of this kind, like the participatory domestication. The domestication of plants that generate non-timber forest products (NTFPs) is a recommended approach to meet their growing demand while ensuring the protection of the resource in the sampling locations (Leakey, 2001). Several studies have been made in the process of domestication of A. floribunda as genetic diversity (Russell et al., 2009; Atangana, 2010), cuttings fragments of leafy stems (Atangana et al., 2006) and grafting (Asaah et al., 2011; World Agroforestry Centre, 2011). But only little information on the biological factors that support the growth of A. floribunda and determine its natural environment regeneration.

In the current state of knowledge, the physiological importance of mycorrhizae is increasingly recognized. Several authors have shown the efficiency of symbiotic microorganisms on plant growth (Diop et al., 2003). These fungi in soils of most ecosystems, form symbiotic associations with the 
Tchinmegni Felenou I et al. "Chemical Property of Soil and Mycorrhizal Status in Allanblackia Floribunda Oliver (Clusiaceae)"

roots of many terrestrial plants (about 80\%) (Strullu, 1991; van der Heijden et al., 1998a). In exchange for carbon resources received from the host plant, these fungi improve the collection and transport to the soles of very few mobile nutrients (mainly phosphorus) (Bolan, 1991), increase drought tolerance (Hardie and Leyton, 1981; Strullu, 1991) and reduce the effects of pathogenic infections (Abdalla and Abdel-Fattah, 2000). Mycorrhizal symbiosis also gives the plant tolerance to heavy metals (Leyval and Joner, 2001) and organic pollutants (Joner and Leyval, 2003). This symbiosis is expressed best in soils low in phosphorus, characteristics of tropical countries.

Incidentally, it is recognized that the soil in the wetlands of Cameroon is acid deficient in Ca, Mo, $\mathrm{Mg}, \mathrm{K}$ and $\mathrm{P}$, and toxicity of $\mathrm{Al}, \mathrm{Fe}$ and Mn (Ambassa-Kiki, 2002). According to the latter author, acid soil covers approximately $75-100 \%$ of this part of Cameroon. Therefore, plants with low root development as A. floribunda should there grow very slowly (Swift, 1998).

In Cameroon the mycorrhizal status of several species is known, including Prunus Africana (Tchietchoua, 2012) and Aucoumea klaineana (Onguene, 2002), but the status of mycorrhizal A. floribunda has not been studied. To remedy this lack, this discussion will describe the type of mycorrhizal fungus that is associated with A. floribunda and evaluate the effect of soil chemical properties on its rhizosphere, its mycorrhizal dependency in its natural range.

\section{MATERIAL AND METHOD}

\section{Study site}

In this study four sites (Mouanko, Yalpenda, Ngoumou, Nkenglikok) were chosen because of the strong representation in this plant species and their belonging to different agro-ecological zones namely: the humid forest zone with a bimodal rainfall ( Ngoumou and Nkenglikok) and the humid forest zone in unimodal rainfall (Mouanko and Yalpenda).

\section{Methodology}

Once in an agro ecological zone, we chose trees based on the factors studied to know the system status (forest and food crop fields and / or fallow more than 3 years), age group (below $50 \mathrm{~cm}$ and greater than or equal to $50 \mathrm{~cm}$ ). In the middle, humidity, temperature, GPS coordinates were also considered. Although not being taken here as a factor, we thought that a correlation with the rate of colonization could help us in interpreting our results. Because according to Alexander (1989), both entities have influences on the rate of colonization and spore density.

\section{Sampling and Harvesting of Soil Samples and Root}

Samples of soil and roots were collected under each tree of rhizosphere areas. About 500 fragments of $2 \mathrm{~cm}$ fine roots (diameter less than or equal to $2 \mathrm{~mm}$ depending Brundret (1996) were harvested and kept in a bottle containing $90^{\circ}$ ethyl alcohol diluted with water to $50 \%$.

The samples of soil and roots were performed as in forests and fields at the foot of saplings and adults. The soil sampling method used was that of Sieverding (1991). Indeed, for each site, the trees A. floribunda were selected randomly. In the root zone of each tree, removal of soil and roots were made to the four cardinal points of the shaft between 0 and $30 \mathrm{~cm}$ in the soil. On each of these points, $550 \mathrm{~g}$ of soil in which are mixed the fragments of roots of A. floribunda were taken by a total of 2.5 $\mathrm{kg}$ for each tree. This soil once removed was introduced into different plastic bags marked, stored and transported at room temperature $\left(250^{\circ} \mathrm{C}\right)$ to the laboratory. The study was conducted according to the following sampling scheme:

\begin{tabular}{|c|c|c|c|c|}
\hline Agro-ecological zone (2) & Population (4) & System (2) & Class circumference (2) & Number of tree \\
\hline \multirow{8}{*}{ monomodal } & \multirow{4}{*}{ Yalpenda } & \multirow{2}{*}{ Disturbed } & $\mathrm{C}<50 \mathrm{~cm}$ & 10 \\
\hline & & & $\mathrm{C} \geq 50 \mathrm{~cm}$ & 10 \\
\hline & & \multirow{2}{*}{ undisturbed } & $\mathrm{C}<50 \mathrm{~cm}$ & 10 \\
\hline & & & $\mathrm{C} \geq 50 \mathrm{~cm}$ & 10 \\
\hline & \multirow{4}{*}{ Mouanko } & \multirow{2}{*}{ Disturbed } & $C<50 \mathrm{~cm}$ & 10 \\
\hline & & & $\mathrm{C} \geq 50 \mathrm{~cm}$ & 10 \\
\hline & & \multirow{2}{*}{ undisturbed } & $\mathrm{C}<50 \mathrm{~cm}$ & 10 \\
\hline & & & $\mathrm{C} \geq 50 \mathrm{~cm}$ & 10 \\
\hline \multirow{2}{*}{ bimodal } & \multirow{2}{*}{ Nkenglikok } & \multirow{2}{*}{ Disturbed } & $\mathrm{C}<50 \mathrm{~cm}$ & 10 \\
\hline & & & $C \geq 50 \mathrm{~cm}$ & 10 \\
\hline
\end{tabular}


Tchinmegni Felenou I et al. "Chemical Property of Soil and Mycorrhizal Status in Allanblackia Floribunda Oliver (Clusiaceae)"

\begin{tabular}{|l|l|l|l|l|}
\hline \multirow{4}{*}{} & \multirow{4}{*}{ undisturbed } & $\mathrm{C}<50 \mathrm{~cm}$ & 10 \\
\cline { 3 - 4 } & & $\mathrm{C} \geq 50 \mathrm{~cm}$ & 10 \\
\cline { 3 - 4 } & \multirow{4}{*}{ Ngoumou } & \multirow{2}{*}{ Disturbed } & $\mathrm{C}<50 \mathrm{~cm}$ & 10 \\
\cline { 3 - 4 } & & $\mathrm{C} \geq 50 \mathrm{~cm}$ & 10 \\
\cline { 3 - 4 } & \multirow{2}{*}{ undisturbed } & $\mathrm{C}<50 \mathrm{~cm}$ & 10 \\
\cline { 3 - 4 } & & $\mathrm{C} \geq 50 \mathrm{~cm}$ & 10 \\
\hline
\end{tabular}

Chemical Analysis of Soil

Soil chemical analyses were conducted to better understand the ecology of arbuscular mycorrhizal fungi in the different study sites. These analyses relevant $\mathrm{pH}$ (potential hydrogen), CEC (cation exchange capacity), the determination of the exchangeable cations, the determination of total nitrogen, available phosphorus, organic carbon, exchangeable aluminum microelements ( $\mathrm{Zn}, \mathrm{Cu}, \mathrm{Fe}$ and $\mathrm{Mn}$ ).

$\mathrm{pH} \mathrm{H}_{2} \mathrm{O}$ was measured for a brine / water solution in a ratio $1 / 2.5$ (ie $1 \mathrm{~g}$ of soil on $2.5 \mathrm{ml}$ of water) with a $\mathrm{pH}$ meter with a glass electrode. The $\mathrm{pH}$ value is directly read on the screen.

The cation exchange capacity $(\mathrm{K}, \mathrm{Mg}$ and $\mathrm{Ca}$ ) represents the sum of exchangeable cations at $\mathrm{pH}$ 7. It was determined in extracts by spectrometry (Benton and Vernon 1990).

Exchangeable cations were extracted with an ammonium acetate solution $(\mathrm{CHOONH})$ at $\mathrm{pH}$ 7. The concentrations of cations were measured by the absorption of light from a hollow cathode lamp. The atomic absorption spectrometer was converted to the absorption at a given concentration (Mehlich, 1984).

The next total nitrogen was determined the method of Buondonno et al., (1995). It was based on ammonification of nitrogen contained in the organic material by digestion in the presence of a strong acid salt, of a catalyst and ammonium levels measured by calorimetry (Anderson and Ingram, 1993).

Available phosphorus was determined by calorimetry water ammonium molybdate and ascorbic acid as reducing agent. The latter was extracted with combination of $\mathrm{HCl}$ and $\mathrm{NaF}$ (Murphy and Riley 1962).

The organic carbon was obtained according to the method described by Heanes (1984). This method is based on oxidation of organic carbon of the acid medium by potassium dichromate. The organic carbon contents were measured by calorimetry.

The exchangeable aluminum, $\mathrm{Al} 3+$ ions are extracted using a $\mathrm{KCl}$ solution. The $\mathrm{Al}$ dosage is made by complexing with aluminum fluoride neutralized by soda as $\mathrm{Al}(\mathrm{OH}) 3$, and titration of hydroxyl (OH-) released with the $\mathrm{HCl}$ solution (Mehlich, 1984).

Micro elements $\mathrm{Zn}, \mathrm{Cu}, \mathrm{Fe}, \mathrm{Mn}$ are removed by the Mehlich (1984) procedure and are determined by the spectrophotometric method of atomic absorption.

\section{Identification of Infections Intra Root}

\section{Washing}

Experience shows that most samples are clean more evaluation is fast and accurate. For that roots were cleaned of soil particles by thorough rinsing under running water in a colander. When he left clods of earth around the roots, these were soaked in a solution of sodium hexametaphosphate (Calgon) for a few minutes that caused the dispersion of particles of earth (Brundrett et al., 1994). Then, only small relatively clear and little Sclerotized roots were selected.

\section{Clarification and Root Coloring}

The roots were systematically lighted coloured before microscopic observation. The lightening technique and Phillips staining and Haymann (1970) was used. The roots were placed in tubes containing a solution of $10 \% \mathrm{KOH}$, in an oven at $90^{\circ} \mathrm{C}$ for 1 hour. They were then thoroughly rinsed with running water, drained and returned to the tubes where they were coated with a trypan blue solution $0.05 \%$ in lactophenol. The tubes were placed in an oven at $90^{\circ} \mathrm{C}$ for 15 minutes. The roots were then thoroughly rinsed and stored in distilled water before mounting.

\section{Installation and observation}

Root fragments of only a few centimeters (2-3) selected at random were collected and mounted in parallel in groups of 10 roots on a blade with three replicates (Toth et al., 1990). The slides were observed under the microscope, each fragment being thoroughly checked throughout its length, the magnifications of 100x and 400x. 
Tchinmegni Felenou I et al. "Chemical Property of Soil and Mycorrhizal Status in Allanblackia Floribunda Oliver (Clusiaceae)"

\section{Evaluation Parameters}

The importance of mycorrhizae was apprehended with the roots of mycorrhizal percentage parameter also called frequency mycorrhization and was determined according to Marx et al., (1977).

\section{$\mathrm{F}(\%)=(\mathrm{nb}$ fragments MYCOR / total fragments nb $) \times 100$}

\section{Statistical Analyses}

Statistical analysis between the different treatments applied during experiments conducted during these works were conducted with several models. The collected data (root colonization and chemical properties of soil) were coded and grouped by topic using the Microsoft Excel version 2013. The software and aggregated data were imported and analysed in SPSS software version 18. Normality tests were conducted. As distributions were not normal for cases of root colonization and chemical properties of soil, arcsinx and $\log$ transformations $(X+1)$ were applied on the two parameters. The data were then subjected to analysis of variance (ANOVA) multivariate. Means were separated using LSD. The general linear model was applied to the analysis of variance with $\mathrm{P}<5 \%$. Pearson correlations between colonization and (the contents of soil chemical elements, humidity, longitude, altitude, latitude and temperature) were performed.

\section{RESULTS}

\section{Type of Mycorrhizal Fungi}

Watching colourful roots, includes mycorrhizal structures: hyphae, vesicles and accessory cells. This indicates an active operation of the symbiosis. A. floribunda is colonized by the mycorrhizal fungi or endomycorrhizae.

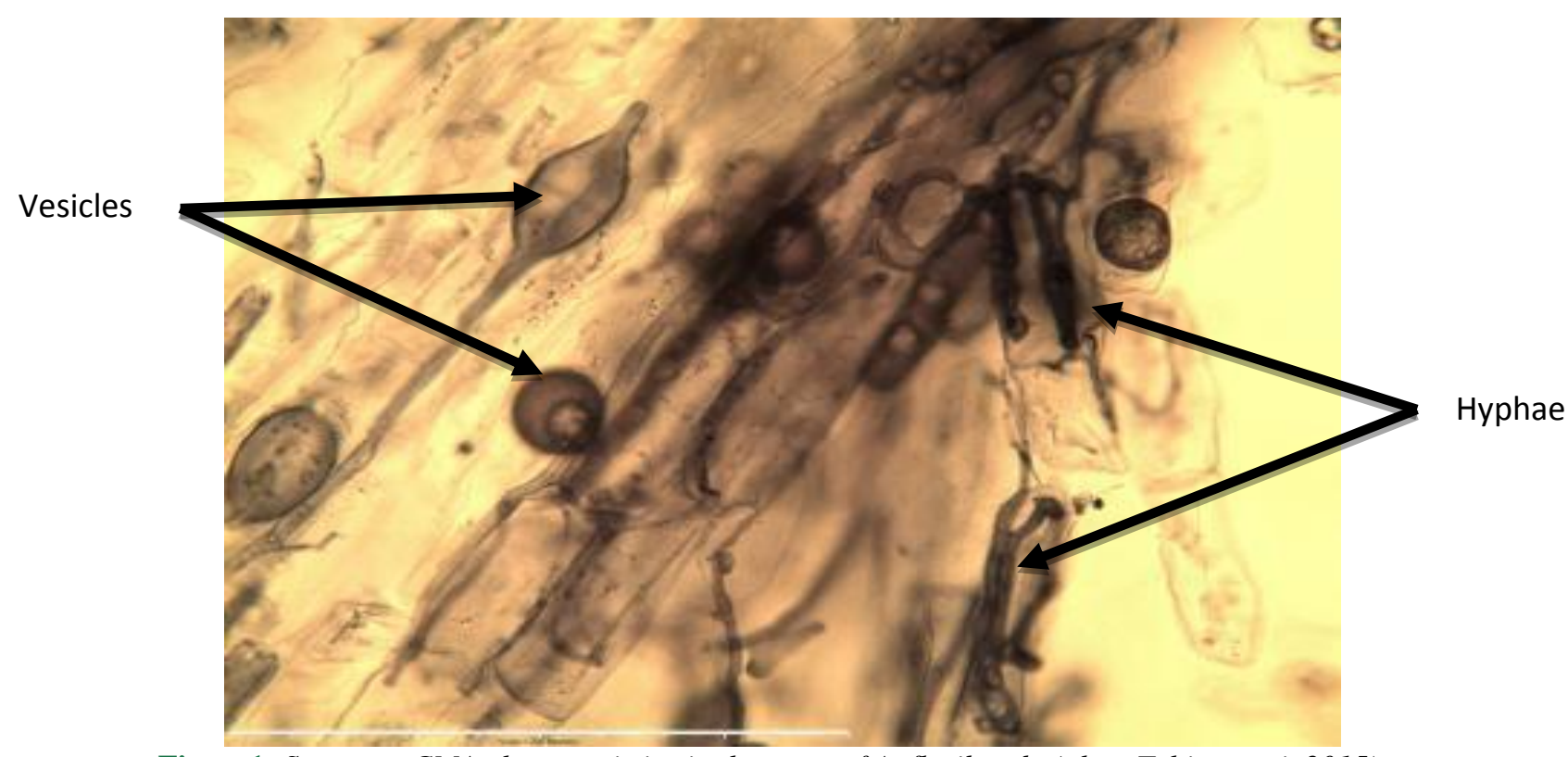

Figure1. Structure CMA characteristics in the roots of A. floribunda (photoTchinmegni, 2015)

\section{Root Colonization}

\section{Effect of Agro-Ecological Zone on Root Colonization Rates}

The highly significant difference $(\mathrm{P}<0.001)$ was observed between the agro-ecological zones. The largest percentage of root colonization was observed in the agro-ecological zone unimodal (35.72 \pm $0.77 \%)$ compared to $(29.21 \pm 0.77 \%)$ of the agro-ecological zone bimodal.

Table1. Variation of root colonization rates by population

\begin{tabular}{|l|l|}
\hline Populations & Colonization rate (\%) \\
\hline Ngoumou & $23.23 \pm 0.7 \mathrm{a}$ \\
\hline Yalpenda & $53.63 \pm 1.33 \mathrm{~b}$ \\
\hline Nkenglikok & $24.35 \pm 0.9 \mathrm{a}$ \\
\hline Mouanko & $33.17 \pm 0.8 \mathrm{c}$ \\
\hline
\end{tabular}

Means followed by the same letter are statistically identical to the probability threshold of 5\% 
Tchinmegni Felenou I et al. "Chemical Property of Soil and Mycorrhizal Status in Allanblackia Floribunda Oliver (Clusiaceae)"

\section{Effect of the Circumference of Class on the Colonization Rate}

The age groups have had a significant influence $(\mathrm{P}<0.001)$ on the rate of colonization of roots of the species. Adult trees or circumferences capacity higher than $50 \mathrm{~cm}$ showed the percent colonization of the roots higher $(35.45 \pm 0.72 \%)$ relative to those of class circumference less than $50 \mathrm{~cm}(30.05 \pm$ $0.75 \%)$.

\section{Effect of System Status on the Rate of Colonization}

The system status has also had a significant influence $(\mathrm{P}<0.001)$ on root colonization of the species. Analyses show a higher colonization rate in the unperturbed system $(35.29 \pm 0.70 \%)$ compared with the perturbed system $(29.96 \pm 0.77 \%)$.

\section{Correlation between Chemical Element Content of the Soil and the Root Colonization Rate}

Table 2 shows the effect of geographical coordinates, the circumferences of trees, and the contents of chemical elements in the soil of the rhizosphere A. floribunda on the rate of root colonization. The correlation between the rate of root colonization and soil chemical elements varies in the rhizosphere of A. floribunda. Indeed, a strong and negative correlation $(\mathrm{r}=-0.93 ; \mathrm{P}=0.04)$ was found between the rate of colonization and copper. A weak positive correlation was obtained between the rate of colonization and longitude $(\mathrm{r}=0.25 ; \mathrm{P}=0.02)$. The correlation between the rate of colonization and the temperature was low and negative $(\mathrm{r}=-0.30 \mathrm{P}=0.003)$. The correlation between moisture and root colonization was low and positive $(\mathrm{r}=0.38 \mathrm{P}=0.03)$.

Table2. Correlation of the effect of chemical elements content of the soil, the circumferences and the geographical coordinates of the colonization rate

\begin{tabular}{|l|l|l|}
\hline \multirow{2}{*}{ dependent variables } & Colonization rates \\
\cline { 2 - 3 } & Coefficient de Pearson & P \\
\hline CHP & 0.068 & 0.389 \\
\hline Latitude & -0.128 & 0.251 \\
\hline Longitude & 0.251 & 0.023 \\
\hline Altitude & 0.094 & 0.398 \\
\hline Temperature & -0.300 & 0.003 \\
\hline Humidity & 0.383 & 0.037 \\
\hline $\mathrm{CO} \%$ & -0.254 & 0.746 \\
\hline $\mathrm{N} \%$ & -0.316 & 0.684 \\
\hline $\mathrm{C} / \mathrm{N}$ & 0.131 & 0.869 \\
\hline $\mathrm{P} \_p p m$ & 0.437 & 0.563 \\
\hline $\mathrm{Al} \_\mathrm{Cmol}(+) / \mathrm{kg}$ & -0.745 & 0.255 \\
\hline $\mathrm{pH} \_\mathrm{H}_{2} \mathrm{O}$ & 0.424 & 0.576 \\
\hline $\mathrm{Ca} \_\mathrm{Cmol}(+) / \mathrm{kg}$ & -0.053 & 0.947 \\
\hline $\mathrm{K} \_\mathrm{Cmol}(+) / \mathrm{kg}$ & -0.425 & 0.575 \\
\hline $\mathrm{Mg} \_\mathrm{Cmol}(+) / \mathrm{kg}$ & -0.362 & 0.638 \\
\hline $\mathrm{Zn} \_\mathrm{ppm}$ & -0.18 & 0.82 \\
\hline $\mathrm{Cu} \_\mathrm{ppm}$ & -0.934 & 0.046 \\
\hline $\mathrm{Mn} \_p p m$ & -0.607 & 0.393 \\
\hline $\mathrm{Fe} \_p p m$ & -0.624 & 0.376 \\
\hline
\end{tabular}

\section{DISCUSSION}

\section{Root Colonization}

The observation of this colourful roots all mycorrhizal structures (hyphae, vesicles, and arbuscules helper cells) which implies that A. floribunda maintains the arbuscular mycorrhizal symbiosis. This statement confirms the fact that in the tropics most trees (about 80\%) are associated with mycorrhizal fungi (Fortin et al., 2008). The presence of the CMA on all trees A. floribunda and all sites show that there is no specificity of infection that is all mycorrhizal structures were observed on all trees colonized roots. In addition, the absence of hairs on the roots of A. floribunda justify colonization rate of its roots.

The highly significant difference was observed between the two agro-ecological zones with the highest percentage of root colonization observed in the agro-ecological zone in unimodal rainfall compared to the agro-ecological zone with a bimodal rainfall. Which joined the work of Onguene, 
Tchinmegni Felenou I et al. "Chemical Property of Soil and Mycorrhizal Status in Allanblackia Floribunda Oliver (Clusiaceae)"

(2000) which showed that the infectious potential of mycorrhizal fungi was higher in wetlands in unimodal rainfall. On the other hand, this root colonization of A. floribunda was also significant in the various target populations with the highest rates of colonization observed Yalpenda while the lowest was observed in Ngoumou. This could be explained by the fact that Yalpenda belongs to the unimodal rainfall areas and therefore the climate is more favorable to mycorrhizal that Ngoumou located in the bimodal part.

In addition, highly significant differences were observed in the systems. The undisturbed soil (forest) have a colonization rate of higher roots compared to disturbed soils. These results corroborate those of Onguene et al., (2000) on the diversity and dynamics of mycorrhizal associations in different system in southern Cameroon. Therefore, we could explain that soil disturbance has a negative influence on root colonization due to the destruction of propagules and certain mycorrhizal strains with chemicals such as pesticides and / or the bush and ploughing lights. Since the presence of arbuscular mycorrhizae in agricultural soils depends on the formation and survival of propagules (hyphae and spores colonized roots). Their persistence in soils is affected by tillage because mycorrhizae are concentrated in the upper soil layers. This argument corroborates that of Kabir (2005), confirming that the tillage breaks the hyphae and diluted. Moreover, inclusion in the cover crop rotations could be colonized by mycorrhizal inoculation increases the potential and density of hyphae. A soil disturbance reduction is accompanied by an increase in root colonization by mycorrhizal fungi.

Subsequently, the age groups have had a significant influence on root colonization of the species. Adult trees with circumferences above $50 \mathrm{~cm}$ showed the percentage of root colonization highest relative to minors and young plants trees with smaller circumferences than or equal to $50 \mathrm{~cm}$. The low rate of colonization among young trees could be due to their very low requirements in minerals and also by adverse environmental conditions during the growing season. Druva-Lusite and Levinsh, (2010) reported that the environmental stress can affect the morphology of the symbiosis. This argument may be valid by ricochet to the adult trees that have their high mycorrhization to their high demand in minerals, because of the anatomy and morphology of the roots can affect the intensity of colonization because the thick roots tend to have high rates of mycorrhiza (Collier et al., 2003). That would justify that the greatest amount of carbohydrates is released by mature trees, resulting attract the fungus able to establish symbiotic relationship (Mekahlia et al., 2013).

\section{Correlation between the Chemical Content of the Soil and Root Colonization}

Mycorrhizal frequency depends on several factors such as the age of the host species, the physicochemical properties of the soil (Escudero and Mendoza 2005; Kessler et al., 2010); Pande and Tarafdar 2004), biogeographic location, seasonal and climatic variations (Bradai et al., 2015; Mekahlia et al., 2013; Pimienta-Barrios et al., 2002), the number of propagules in the soil, and sporulation (Bohrer et al., 2004; Collier et al., 2003).

The chemical characteristic of the soil indicates that A. floribunda adapts to soil very acidic $\mathrm{pH}$ according to the interpretation of standards (Handbook of Agronomy, 1993). Previous studies (Ba et al., 2001; Brundrett, 2004; Calvente et al., 2004) showed that the one factor that could influence the root colonization by mycorhziens fungi in the soil was the soil $\mathrm{pH}$. However, in our analyses differences in the $\mathrm{pH}$ observed between study sites do not have a significant impact on root colonization. Yet the $\mathrm{pH}$ differences have been documented to have an impact on the viability of the spores and not on mycorrhizal symbiosis (Wang et al., 2008). Our results corroborate those of earlier studies that do not show an influence of soil pH on mycorrhizal symbiosis (Wang et al., 2008).

There was no significant difference on the correlation between root colonization and organic matter (organic carbon, total nitrogen). The contents of organic carbon and total nitrogen are very low in the soils studied. These values coincide with those obtained by Voundi (1998) on the floors of the Centre in Cameroon. In addition, the results also corroborate with those found on vitroplants banana in Cameroon (Tsane et al., 2005). These plantlets of banana were more mycorrhizal (root colonization rate of 25\%) on poor soils (low carbon in the soil) as opposed to a rate of $7 \%$ on soil amended with organic matter. This could be explained by adaptation of plants to face stress suffered several kinds (water deficit by low water retention of the soil, due to low soil fertility) in a humid environment (Déziel 2000). The $\mathrm{C} / \mathrm{N}$ calculated different soils gave values that reflect a rapid mineralization of organic matter. This organic matter deficiency could be perceived here as a limitation to sustainable production. 
Tchinmegni Felenou I et al. "Chemical Property of Soil and Mycorrhizal Status in Allanblackia Floribunda Oliver (Clusiaceae)"

The studied soils have low levels of available phosphorus relative to the normal value for acid soils which is between 18 and $20 \mathrm{mg} / \mathrm{kg}$ (Diary of Agronomy, 2006). There is no significant correlation between root colonization and phosphorus. This could be explained by the fact that under the conditions of acidity, phosphorus is present in the form of sparingly soluble compounds such as iron phosphate, aluminium phosphate and the occluded Phosphorus (Hodge et al., 2010). These low phosphorus content available could also be explained by the fact that these soils have a high phosphorus fixing power thus reducing the proportion available to plants. Reducing the colonization of the fungus result from available phosphorus concentration too high or too low contrast (Fernando et al., 2010). Moreover, the presence of a phosphorus source induce a general decline in the absorption of micronutrients, $\mathrm{Fe}, \mathrm{Mn}, \mathrm{Cu}$... This decrease is partially offset when the plant is mycorrhizal.

Trace elements are necessary for plant roots but in reasonable quantities. In soils of the tropics these deficiencies are rare (Anonymous, 2008). The contents of $\mathrm{Fe}, \mathrm{Zn}, \mathrm{Cu}, \mathrm{Mn}$ are very variable in the different sites. In general, Fe and Mn are very abundant in soils. By cons, only the correlation between root colonization and copper was significant. With a high value of correlation coefficient $\mathrm{Cu}$, whatever the soil considered, the percentage of colonization decreases linearly with increasing the proportion of copper. Which negatively affect root colonization. This could be explained by the fact that symbiosis is established and develops gradually with the depletion of nutrients readily available to plant roots in the soil (Strullu 1991). The low levels of $\mathrm{Zn}$ and $\mathrm{Cu}$ could be due to leaching of soluble forms.

\section{CONCLUSION}

The results of this study allowed to mount that the roots of $A$. floribunda are colonized by arbuscular mycorrhizae. The species established mycorrhizal Association throughout its life cycle. The result of the correlation between the copper content and root colonization in this study, suggesting a reduction in the copper substrate, which not only increase the potential of mycorrhizal association and thus improve the growth of cuttings. This study is an important and necessary step prior to inoculation phase and molecular analysis of the roots.

\section{ACKNOWLEDGEMENT}

This work has received financial support from the World Agroforestry Centre, Cameroon. The authors also thank the applied microbiology laboratories of the Institute of Agricultural Research for Development (IRAD) and the laboratory soil analysis of the International Institute of Tropical Agriculture (IITA), which respectively housed the laboratory work.

\section{REFERENCE}

[1] Abdalla ME and Abdel-Fattah GM 2000 Influence of the endo-mycorrhiral fungus Glomus mosseae on the development of peanut pod rots disease in Egypt. Mycorrhiza, 10, 29 -35.

[2] Ambassa-Kiki R, 2002. Caractérisation Biophysique Succincte des différentes Zones Agroécologiques du Cameroun. IRAD, Yaoundé, Cameroun.

[3] Anderson J. M., and Ingram J. S. I. 1993. Tropical soil biology and fertility: a handbook of methods. Second edition. CAB International, the Cambrian News, Aberstwyth, United Kingdom. $221 \mathrm{p}$.

[4] Anegbeh P. O., Tchoundjeu Z., Simons A. J., Roy-Macauley H, 2006. Ecology, production and utilization of Allanblackia floribunda in Nigeria: Paper presented at a Conference on the Theme 'Utilization of Allanblackia, Baobab and Shea nut trees' November 30, 2006, Raw Material Research and Development Council, Nigeria. 17p.

[5] Asaah E. K., Tchoundjeu Z., Ngahane W., Tsobeng A., Kouodiekong L., Jamnadass R., and Simons T, 2011. Allanblackia floribunda - a new oil tree crop for Africa: amenability to grafting New Forest, 41:389- 398 DOI: 10.1007/s11056-010-9230-z

[6] Atangana A. R., Tchoundjeu Z., Asaah E. K., Simons A.J., and Khasa D. P, 2006. Domestication of Allanblackia floribunda: amenability to vegetative propagation: Forest Ecology and Management. 237: 246-251.

[7] Atangana AR, Beaulieu J, and Khasa DP (2010) Wild genetic diversity preservation in a smallsized first generation breeding population of Allanblackia floribunda (Clusiaceae). Tree Genetics \& Genomes, 6: 127-136. 
Tchinmegni Felenou I et al. "Chemical Property of Soil and Mycorrhizal Status in Allanblackia Floribunda Oliver (Clusiaceae)"

[8] Atangana, A.R., and D.P. Khasa. 2008. Preliminary survey of clonal variation in rooting of Allanblackia floribunda leafy stem cuttings. Canadian Journal of Forest Research 38: 10-15.

[9] Ba A., Plenchette C., Danthu P., Duponnois R., and Guissou T, 2001. Functional compatibility of two arbuscular mycorrhozae with thirteen fruit trees in Senegal. Agroforestry Systems, 50: 95105.

[10] Benton Jones J., Vernon W., and Case, 1990. Sampling, handling and analyzing plant tissue samples. In R.L. Westerman (ED) Soil testing and plant Analysis ( $3^{\text {rd }}$ ed). SSSA Book Series No. 3.

[11] Bohrer, K., Friese, C. and Amon, J. 2004. Seasonal dynamics of arbuscular mycorrhizal fungi in differing wetland habitats. Mycorrhiza 14(5): 329-337.

[12] Bonanome A., and Grundy SM, 1988. Effect of dietary stearic acid on plasma cholesterol and lipoprotein levels. N Engl J Med, 318: 1244-1248

[13] Bradai, L., Bissati, S., Chenchouni, H. and Amrani, K. 2015. Effects of climate on the productivity of desert truffes beneath hyper- arid conditions. Int. J. Biometeorol. 59 doi: 10.1007/s00484- 014-0891-8 (In Press).

[14] Brundrett M, 2004. Diversity and classification of mycorrhizal associations, Biol. Rev. 79, $473-$ 495.

[15] Brundrett M. C., Bougher N., Dell B., Grove T., and Malajczuk N, 1996. Working with mycorrhizas in forestry and agriculture. ACIAR Monograph. 32. $374 \mathrm{P}$.

[16] Calvente R., Cano C., Ferrol N., Azcón-Aguilar C., and Barea J, 2004. Analysing natural diversity of arbuscular mycorrhizal fungi in olive tree (Olea europaea L,) plantations and assessment of the effectiveness of native fungal isolates as inoculants for commercial cultivars of olive plantlets, Applied Soil Ecology, 26: 11-19.

[17] Collier, S., Yarnes, C. and Peter Herman, R. 2003. Mycorrhizal dependency of Chihuahuan Desert plants is infuenced by life history strategy and root morphology. J. Arid Environ. 55: 223229.

[18] Déziel M-H, 2000. Influence de l'inoculation endomycorhizienne au champ sur le rendement et la qualité de la pomme de terre (Solanum tuberosum L.). Université de Laval, Canada, mémoire de Master of Science, $112 \mathrm{p}$.

[19] Escudero, V. and Mendoza, R. 2005. Seasonal variation of arbuscular mycorrhizal fungi in temperate grasslands along a wide hydrologic gradient. Mycorrhiza 15(4): 291-299.

[20] Fernando E., Vega F. E., Simpkins A., Aime M. C., Posada F., Peterson S. W., Rehner S. A., Infante F., Castillo A., and Arnold A. E, 2010. Fungal endophyte diversity in coffee plants from Colombia, Hawai'i, Mexico and Puerto Rico. Fungal Ecology, 3 (3): 122-138.

[21] Fortin A., Planchette C. and Piche Y - Les Mycorhizes, la nouvelle révolution verte, Editions Quae, 2008

[22] Heanes D. L. 1984. Determination of organic C in soils by an improved chromic acid digestion and spectrophotometric procedure. Comm. Soil Sci. Plant Anal. 15:1191-1213.

[23] Hodge A., Helgason T., and Fitter H, 2010. Nutritional ecology of arbuscular mycorrhizal fungi. Fungal Ecology, 3(4):267-273.

[24] Joner EJ and Leyval C 2003 Rhizosphere gradients of polycyclic aromatic hydrocarbon (PAH) dissipation in two industrial soils and the impact of arbuscular mycorrhiza. Environmental Science \& Technology, 37, 2371-2375.

[25] Kabir Z, (2005). Tillage or no-tillage: Impact on mycorrhizae. Canadian journal of plant Science, Vol. 85, P 23-29.

[26] Kessler, M., Jonas, R., Strasberg, D. and Lehnert, M. 2010. Mycorrhizal colonizations of ferns and lycophytes on the island of La Réunion in relation to nutrient availability. Basic Appl. Ecol. 11(4): 329-336.

[27] Leakey R.R.B., and Tchoundjeu Z., 2001. Diversification of tree crop: domestication of companion crops for poverty reduction and environmental services. Expl. Agric., 37: 279-296

[28] Leyval C and Joner EJ 2001 Bioavailability of heavy metals in the mycorrhizosphere. Dans: Trace elements in the rhizosphere, CRC Press. pp 165-185. 
Tchinmegni Felenou I et al. "Chemical Property of Soil and Mycorrhizal Status in Allanblackia Floribunda Oliver (Clusiaceae)"

[29] Marx D. H., Bryan W.C., and Cordell C. E, 1977. Survival and growth of pine seedings with Pisolithus tinctorius ectomycorrhizae after two years on reforestation sites in North Carolina and Florida. Forest Sci. 23: 363-373p.

[30] Mehlich M, 1984. Mehlich 3 soil test extractant: a modification of the Mehlich 2 extractant. Comm. Soil Sci. Plant Anal. 15:1409-1416.

[31] Mekahlia, M.N., Beddiar, A. and Chenchouni, H. 2013. Mycorrhizal dependency in the olive tree (Olea europaea) across a xeric climatic gradient. Adv. Environ. Biol. 7(9): 2166-2174.

[32] Murphy J., and Riley J. P, 1962. A modified single solution method for determination of phosphate in natural waters. Analytica Chimica Acta 27:31-36.

[33] Pande, M. and Tarafdar, J.C. 2004. Arbuscular mycorrhizal fungal diversity in neem-based agroforestry systems in Rajasthan. Appl. Soil Ecol. 26(3): 233-241.

[34] Phillips JM and Hayman DS 1970 Improved procedure for clearing roots and staining parasitic and vesicular - arbuscular mycorrhizal fungi for rapid assessment of infection. Transactions British Mycological Society, 55, 158-161.

[35] Pimienta-Barrios, E., Pimienta-Barrios, E., Salas-Galvan, M., Zanudo-Hernandez, J. and Nobel, P. 2002. Growth and reproductive characteristics of the columnar cactus Stenocereus queretaroensis and their relationships with environmental factors and colonization by arbuscular mycorrhizae. Tree Physiol. 22(9): 667-674.

[36] Russell J. R., Kadu CAC., Jamnadass R., Booth A., Cordeiro N. J., Woodhead M., Dawson I. K, 2009. AFLP and SSR diversity in the African fruit tree Allanblackia: implications for management of a genus newly subject to domestication for the edible oil industry. Tree Genetics \& Genomes, 5: 517-527.

[37] Sieverding E, 1991.Vesicular-arbuscular mycorrhiza Management. In Tropical Agrosystems. GTZ n 224 FRG. 281p.

[38] Strullu D. G, 1991. Les mycorhizes des arbres et des plantes cultivées. Edition Lavoisier: Paris, France; p. 250.

[39] Tchietchoua Y. H, 2012. Étude morphologique et moléculaire des champignons mycorhiziens à arbuscules (CMA) associés à Prunus africana (Hook.f.) Kalkman dans deux zones agroécologiques du Cameroun. Mémoire de master : Université de Yaoundé, 97 p.

[40] Tsané G., Fogain R., Achard R., Foko J, 2005. Impact de la mycorhization arbusculaire sur la croissance de vitroplants de plantain, testée sur des sols de fertilité différente en conditions contrôlées au Cameroun, Fruits, 60: 303-309.

[41] Voundi J. C, 1998. Utilisation des déchets de l'industrie du bois en vue de l'amélioration de la fertilité chimique des sols acides tropicaux. Th. PhD. Univ. Gent. PP 59-88.

[42] Wang, G.M., Stribley, D.P., Tinker, P.G. \& Walker, C. 2008. Soil pH and vesicular-arbuscular mycorrhizae, In Ecological Received: Interactions in Soil, edited by Fitter, A.H. Oxford: Blackwell Accepted: pp. 219-224. 